\title{
Gastric perforation following cytoreductive surgery and perioperative intraperitoneal chemotherapy: a case series of six
}

\author{
Lee S. Kyang ${ }^{1 *}$, Nayef A. Alzahrani ${ }^{1,2}$, Jing Zhao ${ }^{1}$ and David L. Morris ${ }^{1}$
}

\begin{abstract}
Background: Incidence of gastric perforation following cytoreductive surgery (CRS) and perioperative intraperitoneal chemotherapy (PIC) is not widely reported.

Methods: Suitable patients were identified from our database of 1028 procedures. Relevant information was then gathered via medical records and operation reports for these patients.

Results: Six patients suffered early postoperative gastric perforation following the procedure (0.58\%), all of whom received heated intraoperative intraperitoneal chemotherapy (HIPEC). Surgical exploration revealed protrusion of nasogastric (NG) tube through stomach wall defects which were either located at or near the greater curvature of stomach. These patients were managed successfully with operation, and no mortality was recorded.

Conclusions: Gastric perforation following CRS and PIC is most likely the result of a multifactorial process. To reduce the risk of such complication, avoiding nasogastric suction in these patients may prove helpful. Any suspected perforated viscus must be addressed promptly to avoid unwanted morbidity and mortality from the procedure. To our knowledge, conservative management has not been documented to work in this subgroup and surgery remains the mainstay of treatment.
\end{abstract}

Keywords: Peritonectomy, Nasogastric tube, Suction, Heated intraoperative intraperitoneal chemotherapy, HIPEC, Appendiceal cancer, Gastric perforation, Stomach

\section{Background}

Historically, the prognosis of peritoneal dissemination of neoplasms (primary or metastatic), also known as peritoneal carcinomatosis (PC), was poor. Over the past few decades, the introduction of cytoreductive surgery (CRS) and perioperative intraperitoneal chemotherapy (PIC) has significantly altered the treatment landscape for PC and, owing to its promising survival benefits [1-3], the combination treatment has gained popularity. Essentially, there are two major components to the procedure: first, CRS involves removal of macroscopic tumour off the peritoneum and/or visceral organs; then, intraoperative chemotherapy (HIPEC) or postoperative chemotherapy

\footnotetext{
* Correspondence: frank.ls01@hotmail.com

'Department of Surgery, St. George Hospital, University of New South Wales, Sydney, New South Wales, Australia

Full list of author information is available at the end of the article
}

(EPIC) allows a high concentration of cytotoxic drug to destroy microscopic residual disease [4].

Despite well-documented survival results, perception towards the therapeutical approach remains sceptical due partly to its high toxicity [5]. However, clinical experience has allowed surgeons to improve the outcomes. A study at St. George Hospital in Sydney, which prospectively studied 140 patients who underwent CRS and PIC, demonstrated a significant reduction in morbidity from 30 to $10 \%$ and mortality from 7 to $1 \%$ when the former 70 patients were compared to latter 70 patients [6]. This data suggests a learning curve effect associated with the procedure. We have now done 1000 procedures and have a mortality of approximately $1 \%$ in the last 4 years.

The high morbidity and mortality rates of such intervention can be largely attributed to the surgery and/or chemotherapy [7]. Multiple body systems can be impacted and gastrointestinal complications are the most 
prevalent including abscess (0-37\%), fistula (0-23\%), ileus $(0-86 \%)$, anastomotic leak $(0-9 \%)$ and bowel perforation $(0-10 \%)$ [4]. To our knowledge, there are, however, only a few reports of gastric perforation in these patients. Here we outline and evaluate our experience with six patients complicated by gastric perforation following CRS and PIC.

\section{Methods}

We retrospectively explore a prospectively maintained database of 843 patients, amounting to 1028 procedures, who underwent CRS and perioperative chemotherapy for intraperitoneal dissemination of primary cancers at St. George Hospital (Sydney) from 1996 to June 2016 to identify patients with postoperative gastric perforation. Medical records and operation reports for the identified patients were then reviewed to gather relevant information for this case series. All our patients are preoperatively consented to have information stored in our database for research purposes (by South Eastern Sydney Local Health District Human Research Ethics Committee).

\section{Results}

All the procedures were done by one surgical team. These patients were reviewed by a multidisciplinary team of surgical oncologists, medical oncologists, anaesthetist, radiologists, nurses and allied health members.
So far, six incidents of postoperative gastric perforations were reported following CRS and perioperative chemotherapy. The patients consisted of two men and four women with a mean age of 50.7 (41-62 years old), representing an incidence of $0.58 \%$ (6/1028) from our database. The initial CRS were performed to remove pseudomyxoma peritoneii (appendiceal neoplasm) in three patients, peritoneal mesothelioma in one patient and ovarian cancer in the remaining two. During the surgeries, variable procedures were done (Table 1), determined by the distribution, volume and invasion of PC. Mean peritoneal cancer index (PCI), as defined by Jacquet and Sugarbaker [8], was 27.5 in these patients. A mean time of $9.6 \mathrm{~h}$ was required to operate on these patients.

Hyperthermic intraoperative intraperitoneal chemotherapy (HIPEC) was introduced in all six patients. Hyperthermic mitomycin $\mathrm{C}$ was given to patients 1 and 3 , hyperthermic cisplatin was given to patients 2 and 4 and hyperthermic oxaliplatin was used in patients 5 and 6 . In contrast, only one patient received early postoperative intraperitoneal 5-fluorouracil (patient 3) for a total of 5 days. Following the procedure, proton pump inhibitor (PPI) was prescribed for these patients till they are mobilised or discharged from hospital.

Diagnosis of gastric perforation was confirmed by direct visualisation of stomach wall defect. It took us a mean time of 6 days postoperatively to diagnose possible

Table 1 Characteristics of patients with gastric perforation following CRS and PIC at a tertiary referral centre (St. George Hospital) in Sydney

\begin{tabular}{|c|c|c|c|c|c|c|}
\hline $\begin{array}{l}\text { Patient number; } \\
\text { age; gender }\end{array}$ & Diagnosis & Procedures performed & $\mathrm{PCl}^{\mathrm{a}}$ & HIPEC $^{\mathrm{b}}$ (chemotherapy) & $\mathrm{EPIC}^{\mathrm{C}}$ & $\begin{array}{l}\text { Length of } \\
\text { surgery (hours) }\end{array}$ \\
\hline $1 ; 62 ; M$ & $\begin{array}{l}\text { Pseudomyxoma } \\
\text { peritoneii (redo) }\end{array}$ & Peritonectomy, small bowel resection & 17 & Yes $\left(M M C^{d}\right)$ & No & 8.5 \\
\hline $2 ; 58 ; F$ & Ovarian cancer & $\begin{array}{l}\text { Peritonectomy, splenectomy, cholecystectomy, partial } \\
\text { gastrectomy with Roux-En-Y anastomosis, small bowel } \\
\text { resection, bilateral diaphragm strip }\end{array}$ & 32 & Yes (CDDPe) & No & 10.5 \\
\hline $3 ; 41 ; F$ & $\begin{array}{l}\text { Pseudomyxoma } \\
\text { peritoneii }\end{array}$ & $\begin{array}{l}\text { Peritonectomy, splenectomy, cholecystectomy, } \\
\text { omentectomy, right hemicolectomy }\end{array}$ & 14 & Yes (MMC) & Yes & 10.0 \\
\hline $4 ; 51 ; F$ & $\begin{array}{l}\text { Peritoneal } \\
\text { mesothelioma }\end{array}$ & $\begin{array}{l}\text { Peritonectomy, bilateral diaphgram stripping, } \\
\text { splenectomy, right hemicolectomy, cholecystectomy, } \\
\text { segment II liver resection, pelvic stripping, omentectomy }\end{array}$ & 33 & Yes (CDDP) & No & 9.0 \\
\hline $5 ; 44 ; \mathrm{M}$ & $\begin{array}{l}\text { Pseudomyxoma } \\
\text { peritoneii }\end{array}$ & $\begin{array}{l}\text { Peritonectomy, bilateral diaphragmatic stripping, } \\
\text { splenectomy, pancreas stripping, liver surface stripping, } \\
\text { cholecystectomy, Billroth I gastrectomy, right } \\
\text { hemicolectomy, anterior resection }\end{array}$ & 39 & Yes $\left(O X^{f}\right)$ & No & 12.0 \\
\hline $6 ; 48 ; \mathrm{F}$ & Ovarian cancer & $\begin{array}{l}\text { Peritonectomy, oophorectomy, salpingectomy, } \\
\text { salpingooophorectomy, removal of ligaments (ovarian, } \\
\text { paraovarian, fimbrial or broad ligaments), hysterectomy } \\
\text { with rectum, bilateral diaphragm stripping, splenectomy, } \\
\text { partial gastrectomy, left hepatectomy and creation of } \\
\text { colostoma }\end{array}$ & 30 & Yes (OX) & No & 7.8 \\
\hline
\end{tabular}

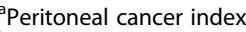

${ }^{\mathrm{b}}$ Hyperthermic intraperitoneal chemotherapy

${ }^{\mathrm{C}}$ Early postoperative intraperitoneal chemotherapy

${ }^{\mathrm{d}}$ Mitomycin C

${ }^{e}$ Cisplatin

foxaliplatin
} 
Table 2 Operative and post-operative characteristics of the same set of patients

\begin{tabular}{|c|c|c|c|c|c|c|}
\hline $\begin{array}{l}\text { Patient number; } \\
\text { age; gender }\end{array}$ & $\begin{array}{l}\text { Time from initial } \\
\text { CRS to perforation } \\
\text { diagnosis (days) }\end{array}$ & Indications of perforated viscus & $\begin{array}{l}\text { Surgery or } \\
\text { conservative }\end{array}$ & $\begin{array}{l}\text { Location of stomach } \\
\text { perforation }\end{array}$ & How was it fixed? & $\begin{array}{l}\text { Length of } \\
\text { hospital } \\
\text { stay (days }\end{array}$ \\
\hline $1 ; 62 ; M$ & 2 & Brown fluid in drain & Surgery & $\begin{array}{l}5 \mathrm{~mm} \text { adjacent to liver } \\
\text { edge }\end{array}$ & $\begin{array}{l}\text { Oversewn with } \\
\text { vicryl }\end{array}$ & 24 \\
\hline $2 ; 58 ; F$ & 9 & $\begin{array}{l}\text { Ongoing peritonism with brownish } \\
\text { discharge from abdominal wound } \\
\text { despite unremarkable } C T\end{array}$ & Surgery & $\begin{array}{l}\text { Above } \\
\text { gastroenterostomy }\end{array}$ & $\begin{array}{l}\text { Oversewn then } \\
\text { with diaphragm } \\
\text { patch }\end{array}$ & 55 \\
\hline $3 ; 41 ; F$ & 7 & $\begin{array}{l}\text { Peritonism, green billous fluid in } \\
\text { drain }\end{array}$ & $\begin{array}{l}\text { Conservative } \\
\text { then surgery }\end{array}$ & Stomach body & $\begin{array}{l}\text { Oversewn with } \\
\text { vicryl }\end{array}$ & 44 \\
\hline $4 ; 51 ; F$ & 10 & $\begin{array}{l}\text { Peritonism, } C T \text { abdomen, green } \\
\text { billous fluid in drain }\end{array}$ & Surgery & $\begin{array}{l}3 \mathrm{~mm} \text {, greater curvature } \\
\text { of stomach }\end{array}$ & $\begin{array}{l}\text { Oversewn with } \\
\text { menseteric fat }\end{array}$ & 26 \\
\hline $5 ; 44 ; M$ & 6 & Peritonism, CT abdomen & Surgery & $\begin{array}{l}5 \mathrm{~mm} \text {, greater curvature } \\
\text { of proximal stomach }\end{array}$ & $\begin{array}{l}\text { Oversewn with } \\
\text { vicryl and plication }\end{array}$ & 34 \\
\hline $6 ; 48 ; F$ & 3 & Green billous fluid in drain & Surgery & $\begin{array}{l}5 \mathrm{~mm} \text {, posterior gastric } \\
\text { wall } 1 \mathrm{~cm} \text { away from } \\
\text { greater curvature }\end{array}$ & $\begin{array}{l}\text { Oversewn with } \\
\text { vicryl and plication }\end{array}$ & 35 \\
\hline
\end{tabular}

perforated viscus in these patients based on signs of peritonitis, fluid content in drain and $\mathrm{CT}$ abdomen (Table 2). These patients were brought to theatre for exploration and closure of perforation. We tried conservative management on one patient (patient 3), however, with no clinical improvement. Ultimately, she underwent surgical exploration to fix the perforation.

All gastric perforations were either located at or near the greater curvature of stomach (Fig. 1). The sizes of the defects were no more than $0.5 \mathrm{~cm}$ in diameter and NG tube was seen protruding through the stomach, causing bile peritonitis in all cases. The defects were repaired by suturing the perforation on two layers. The outcome for these patients was positive with no mortality. The mean length of hospital stay for these patients was 36 days. Patient 2 had the longest in-hospital admission (55 days) due to concurrent complications of gastrointestinal bleeding and intra-abdominal abscess.

\section{Discussion}

We retrospectively explored the incidence of gastric perforation following CRS and PIC from our prospective database. In our institution, out of the 1028 procedures performed in the last two decades, six patients $(0.58 \%)$ had postoperative recovery complicated by gastric perforation. These patients were taken back to theatre for emergency repair of perforated viscus. All gastric perforations were either at or near the greater curvature of stomach. Fortunately, all of them achieved complete resolution and the mean length of hospital stay for these patients was 36 days. In contrast to bowel perforation, postoperative gastric perforation associated with CRS and PIC is a relatively rare surgical complication. To our knowledge, this has not been widely reported in the literature. So far, only eight patients were described to have gastric perforation following CRS and PIC (Table 3).
The location of stomach defect at or near the greater curvature indicates possible pathology at that area. All our patients, except patient 1, had either omentectomy, splenectomy or both done during the procedure. During the procedure, ligations of right and left gastroepiploic vessels (greater omentectomy) and splenic vessels (splenectomy) reduce perfusion of greater curvature,

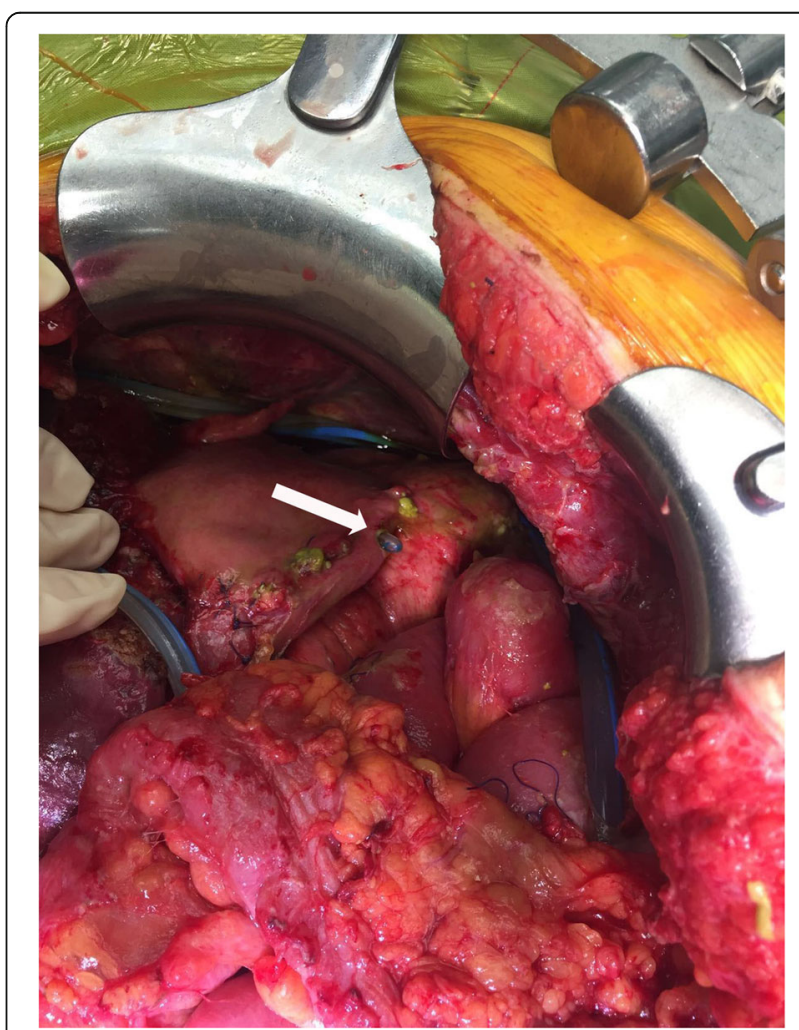

Fig. 1 Postoperative nasogastric tube perforation (arrow), through the greater curvature of stomach, leading to bile peritonitis in patients who underwent CRS and HIPEC 


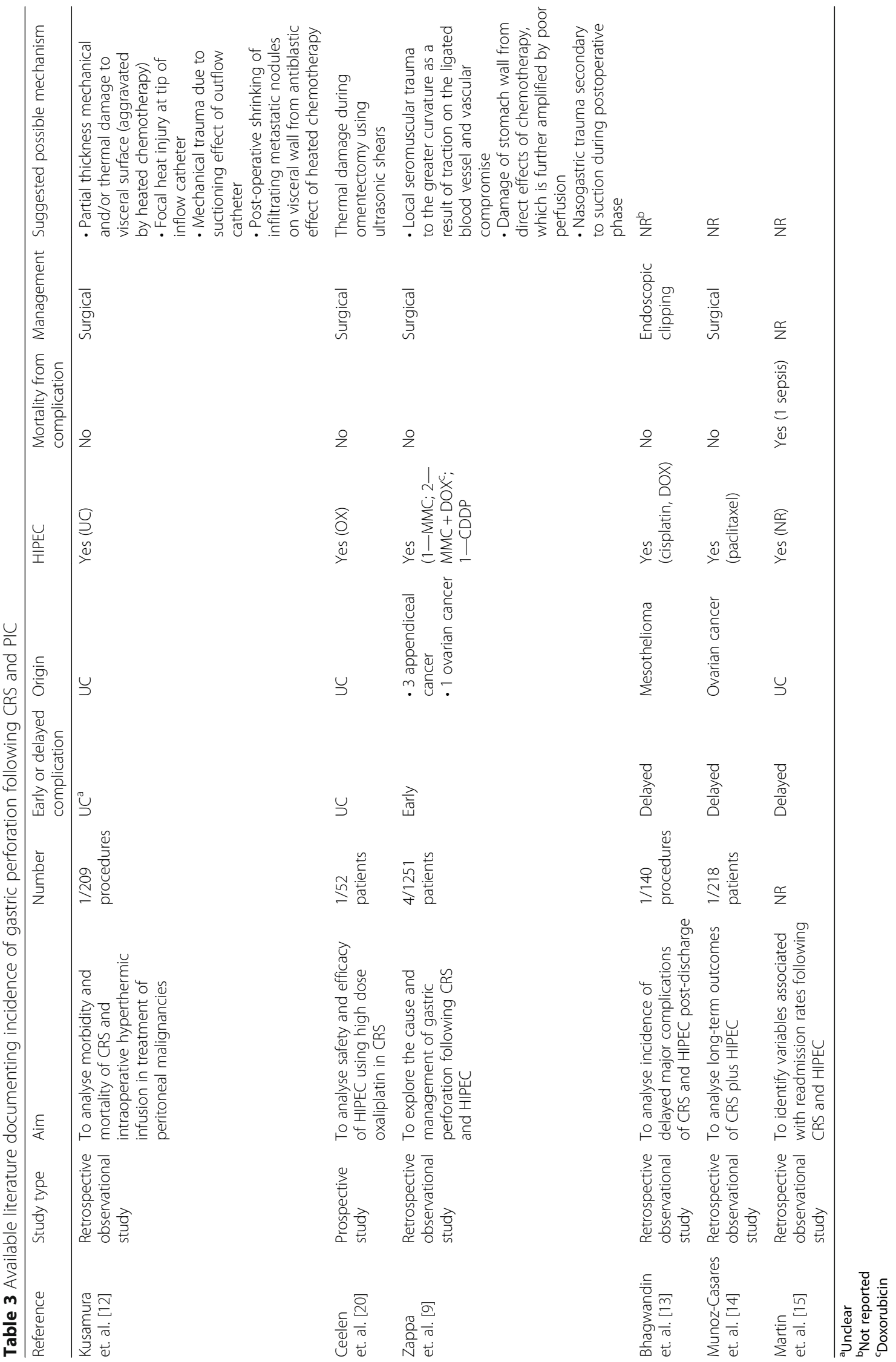


resulting in seromuscular trauma at site of ligation due to traction [9]. We also strongly believe that the injury may be associated with nasogastric tube based on the visualisation of tube protrusion through the stomach defects during exploratory laparotomy. Perhaps it was related to pressure ischemia exerted on stomach mucosa by nasogastric tube suction and by relatively rigid nasogastric tubes [10]. Other proposed mechanisms include direct effect of intraperitoneal chemotherapy [11] and thermal injury caused by inflow and outflow catheters during infusion of HIPEC [12]. All these factors, ultimately, lead to friability of stomach wall making it susceptible to perforation.

Postoperative monitoring for any indication of perforated viscus is paramount. Signs of peritonitis, fluid content in intraperitoneal drain and CT abdomen can be useful to guide our suspicion. We would like to highlight, though, that false negative is still possible on CT abdomen and complete clinical presentation must be taken into account to establish index of suspicion, in addition to imaging. For instance, in patient 2, we decided to perform surgical exploration due to continuous sepsis (temperature $>40{ }^{\circ} \mathrm{C}$ ) and feculent discharge from abdominal wound despite unremarkable CT finding. In contrast, the delayed diagnosis in patient 4 was rather unfortunate. Spiked temperature postoperatively was initially thought to result from hospital-acquired pneumonia (Pseudomonas-positive on sputum culture). Because of unresolved fever despite being on optimal antibiotic therapy, an abdominal CT imaging was performed, which showed a defect in lateral wall of stomach, and an urgent surgical intervention was conducted. Surprisingly, the patient's recovery was unremarkable and had a relatively short postsurgical stay.

All six gastric perforations were diagnosed in the early postoperative phase (mean of 6 days). However, there were at least three incidents of gastric perforation described in the literature that manifested as a long-term complication of CRS and PIC [13-15]. The documented events occurred following discharge of patients from hospital. At our institution, all patients are monitored monthly for the first 3 months after discharge and six monthly thereafter, during which clinical examination and review of pertinent tumour markers are conducted. Thus far, we have not encountered a single case of gastric perforation throughout follow-up period following discharge for patients with CRS and PIC. However, we acknowledge and concur with Bhagwandi et al. [13] that possible occurrence of such life-threatening complication while patients are no longer monitored by the treating surgeon could lead to unnecessarily high morbidity and mortality. Therefore, follow-up schedule should be well established in each peritonectomy institution to track patients' postoperative progress.
Nonoperative management of gastric perforation was proven to be viable by Crofts et al. [16] in managing patients with perforated gastric ulcer, dating back to 1989 . It has been studied extensively in patients with perforated peptic ulcers, and the results have been promising when compared to operative management $[17,18]$. This alternative can be executed by keeping the stomach empty through a strict nil-by-mouth regime and nasogastric aspiration, in adjunct with close monitoring of patient's clinical status and administration of antibiotic and PPI [19]. We tried conservative management on one patient (patient 3). A lack of clinical improvement prompted immediate surgical intervention. Similarly, as outlined in Table 3, none of the patients were managed conservatively in the literature. As the nonoperative management hinges on allowing the perforated site to heal and seal by itself [19], the impact of HIPEC on this is currently not clear. Regardless of the mechanism, CRS and HIPEC are suggested to result in a weaker stomach wall, at least in the immediate postoperative phase. It would be sensible to refrain exerting more pressure on the stomach mucosa. Therefore, we propose to avoid suction on NG tubes following the procedure.

\section{Conclusions}

Gastric perforation is a rare surgical complication following CRS and PIC, and it is most likely the result of a multifactorial process. To reduce the risk of such complication, avoiding nasogastric suction in these patients may prove helpful. Nevertheless, any suspected perforated viscus must be addressed promptly to avoid unwanted morbidity and mortality from the procedure. To our knowledge, conservative management has not been documented to work in this subgroup and surgery remains the mainstay of treatment.

\section{Abbreviations \\ CRS: Cytoreductive surgery; HIPEC: Heated intraoperative intraperitoneal chemotherapy; PC: Peritoneal carcinomatosis; PCl: Mean peritoneal cancer index; PPI: Proton pump inhibitor}

\section{Acknowledgement}

Not applicable.

\section{Funding}

This research did not receive any specific grant from funding agencies in the public, commercial or not-for-profit sectors.

Availability of data and materials

All data will be provided in the submitted tables.

Authors' contributions

LK is the main author. NA and JZ were involved in the editing of the paper and data collection. DLM was involved in the study design and patient recruitment. All authors read and approved the final manuscript.

Competing interests

The authors declare that they have no competing interests. 


\section{Consent for publication}

All patient data was consented for use in publication.

\section{Ethics approval and consent to participate}

All our patients are preoperatively consented to have information stored in our database for research purposes (by South Eastern Sydney Local Health District Human Research Ethics Committee).

\section{Author details}

${ }^{1}$ Department of Surgery, St. George Hospital, University of New South Wales, Sydney, New South Wales, Australia. ${ }^{2}$ Imam Muhammad ibn Saud Islamic University College of Medicine, Riyadh, Saudi Arabia.

Received: 5 October 2016 Accepted: 1 February 2017

Published online: 10 February 2017

\section{References}

1. Franko J, Ibrahim Z, Gusani NJ, Holtzman MP, Bartlett DL, Zeh III HJ. Cytoreductive surgery and hyperthermic intraperitoneal chemoperfusion versus systemic chemotherapy alone for colorectal peritoneal carcinomatosis. Cancer. 2010;116:3756-62.

2. Glehen O, Gilly FN, Arvieux C, Cotte E, Boutitie F, Mansvelt B, Bereder JM, Lorimier G, Quenet F, Elias D, Association Francaise de Chirurgie. Peritoneal carcinomatosis from gastric cancer: a multi-institutional study of 159 patients treated by cytoreductive surgery combined with perioperative intraperitoneal chemotherapy. Ann Surg Oncol. 2010;17:2370-7.

3. Verwaal VJ, Ruth S, Bree E, Slooten GW, Tinteren H, Boot H, Zoetmulder FAN. Randomized trial of cytoreduction and hyperthermic intraperitoneal chemotherapy versus systemic chemotherapy and palliative surgery in patients with peritoneal carcinomatosis of colorectal cancer. J Clin Oncol. 2003:21:3737-43.

4. Chua TC, Yan TD, Saxena A, Morris DL. Should the treatment of peritoneal carcinomatosis by cytoreductive surgery and hyperthermic intraperitoneal chemotherapy still be regarded as a highly morbid procedure? A systematic review of morbidity and mortality. Ann Surg. 2009:249:900-7.

5. Mehta SS, Gelli M, Agarwal D, Goere D. Complications of cytoreductive surgery and HIPEC in the treatment of peritoneal metastases. Indian Assoc Surg Oncol. 2016;7:225-9.

6. Yan TD, Links M, Fransi S, Jacques T, Black D, Saunders V, Morris DL. Learning curve for cytoreductive surgery and perioperative intraperitoneal chemotherapy for peritoneal surface malignancy - a journey to becoming a nationally funded peritonectomy center. Ann Surg Oncol. 2007;14:2270-80.

7. Baratti D, Kusamura S, Laterza B, Balestra MR, Deraco M. Early and long-term postoperative management following cytoreductive surgery and hyperthermic intraperitoneal chemotherapy. World J Gastrointest Oncol. 2010;2:36-43.

8. Jacquet $\mathrm{P}$, Sugarbaker $\mathrm{PH}$. Clinical research methodologies in diagnosis and staging of patients with peritoneal carcinomatosis. Cancer Treat Res. 1996; 82:359-74.

9. Zappa L, Savady R, Sugarbaker PH. Gastric perforation following cytoreductive surgery with perioperative intraperitoneal chemotherapy. J Surg Oncol. 2010;101:634-6.

10. Daliya P, White TJ, Makhdoomi KR. Gastric perforation in an adult male following nasogastric intubation. Ann R Coll Surg Engl. 2012;94:e210-2.

11. Carter J, Durfee J. A case of bowel perforation after neoadjuvant chemotherapy for advanced epithelial ovarian cancer. Gynecol Oncol. 2007:107:586-9.

12. Kusamura S, Younan R, Baratti D, Costanzo P, Favaro M, Gavazzi C, Deraco M. Cytoreductive surgery followed by intraperitoneal hyperthermic perfusion analysis of morbidity and mortality in 209 peritoneal surface malignancies treated with closed abdomen technique. Am Cancer Soc. 2006;106:1144-53

13. Bhagwandin SB, Naffouje S, Salti G. Delayed presentation of major complications in patients undergoing cytoreductive surgery plus hyperthermic intraperitoneal chemotherapy following hospital discharge. J Surg Oncol. 2015;111:324-7.

14. Munoz-Casares FC, Medina-Fernandez FJ, Arjona-Sanchez A, Casado-Adam A, Sanchez-Hidalgo JM, Rubio MJ, Ortega-Salas R, Munoz-Villanueva MC, Rufian-Pena S, Briceno FJ. Peritonectomy procedures and HIPEC in the treatment of peritoneal carcinomatosis from ovarian cancer: long-term outcomes and perspectives from a high-volume center. Eur J Surg Oncol. 2015;42:224-33.
15. Martin AS, Abbott DE, Hanseman D, Sussman JE, Kenkel A, Greiwe P, Saeed N, Ahmad SH, Sussman JJ, Ahmad SA. Factors associated with readmission after cytoreductive surgery and hyperthermic intraperitoneal chemotherapy for peritoneal carcinomatosis. Ann Surg Oncol. 2016;23:1941-7.

16. Crofts TJ, Park KGM, Steele RJC, Chung SC, Li AKC. A randomized trial of nonoperative treatment for perforated peptic ulcer. New Engl J Med. 1989;320:15

17. Cao F, Li J, Li A, Fang Y, Wang Y-J, Li F. Nonoperative management for perforated peptic ulcer: who can benefit? Asian J Surg. 2014;37:148-53.

18. Dascalescu C, Andriescu L, Bulat C, Danilla R, Dodu L, Acornicesei M, Radulescu C. Taylor's method: a therapeutic alternative for perforated gastroduodenal ulcer. Hepatogastroenterology. 2006;53:543-6.

19. Hanumanthappa MB, Gopinathan S, Rai DG, Dsouza N. A non-operative treatment of perforated peptic ulcer: a prospective study with 50 cases. J Clin Diagn Res. 2012:6:696-9.

20. Ceelen WP, Peeters M, Houtmeyers P, Breusegem FD, Pattyn P. Safety and efficacy of hyperthermic intraperitoneal chemoperfusion with high-dose oxaliplatin in patients with peritoneal carcinomatosis. J Clin Diagn Res. 2008;15:535-41.

\section{Submit your next manuscript to BioMed Central and we will help you at every step:}

- We accept pre-submission inquiries

- Our selector tool helps you to find the most relevant journal

- We provide round the clock customer support

- Convenient online submission

- Thorough peer review

- Inclusion in PubMed and all major indexing services

- Maximum visibility for your research

Submit your manuscript at www.biomedcentral.com/submit 